\title{
Variabilidade espacial de atributos e perda de solo na definição de zonas de manejo ${ }^{1}$
}

\author{
Daniela Popim Miqueloni², Eduardo Mônaco Gianello ${ }^{3}$, Célia Regina Paes Bueno ${ }^{3}$
}

\begin{abstract}
Spatial variability of attributes and soil loss in the definition of management zones

Management zones are the result of proper planning of soil use and occupation, which reduce the human impact on the environment. This study aimed to characterize chemical and physical soil traits and check possible management zones through the spatial variability of soil loss estimates and limiting attributes to the development of crops, determining the factors that most affect the erosion process. A total of 258 soil georeferenced points were sampled and had their chemical and physical characteristics determined. The soil losses were estimated by using the USLE model; erosion natural potential, risk and expectation; and anthropic factor of soil loss. The spatial variability of these characteristics was analyzed by descriptive statistics and geostatistics. The results indicated high soil loss, low erosion natural potential and moderate erosion risk for most of the area, with major losses in the convex landform. The anthropic factor and the expected erosion indicate inadequate use and occupation, particularly for the management of soil $\mathrm{pH}$ for citrus crop. The anthropic factors were important for the spatial analysis of erosion expectation, suggesting specific management zones.
\end{abstract}

KEY-WORDS: Geostatistics; erosion; land use.

\section{INTRODUÇÃO}

Na década de 1990, Oldeman et al. (1991) já indicavam que $15 \%$ da superfície global estava degradada, com as maiores proporções na Europa (25\%), Ásia (18 \%) e África (16\%), sendo a erosão do solo responsável por $83 \%$ desse total. Atualmente, estudos apontam que esse processo físico, relacionado ao ambiente socioeconômico, político e cultural, tem sido acelerado por fatores econômicos

\section{RESUMO}

Zonas de manejo são o resultado de um planejamento adequado de uso e ocupação do solo, que reduz os impactos do homem sobre o meio ambiente. Este trabalho objetivou caracterizar o solo química e fisicamente, bem como verificar possíveis zonas de manejo, por meio da variabilidade espacial de estimativas de perda de solo e de atributos limitantes ao desenvolvimento de culturas, determinando os fatores de maior atuação no processo erosivo. Foram amostrados 258 pontos georreferenciados de solo, os quais tiveram seus atributos químicos e físicos determinados. As perdas de solo foram estimadas por meio do modelo USLE; potencial natural, risco e expectativa de erosão; e fator antrópico de perda de solo. A variabilidade espacial desses atributos foi analisada por meio de estatística descritiva e geoestatística. Os resultados indicaram alta perda de solo, baixo potencial natural de erosão e moderado risco de erosão, para a maior parte da área, com perdas maiores na pedoforma convexa. $\mathrm{O}$ fator antrópico e a expectativa de erosão indicam uso e ocupação inadequados, principalmente quanto ao manejo do $\mathrm{pH}$ do solo, para a cultura de citros. Os fatores antrópicos foram determinantes na análise espacial da expectativa de erosão, sugerindo zonas de manejo específico.

PALAVRAS-CHAVE: Geoestatística; erosão; uso do solo.

e demográficos, principalmente em países em desenvolvimento, como a Índia, China e Brasil (Bouaziz et al. 2011). O uso inadequado e a intensa mecanização agravam esse processo, o que afeta a produtividade agrícola, além de causar degradação ambiental e esgotamento de recursos naturais. Conhecer e entender esses processos de deterioração ambiental é de extrema importância para mapear e controlar seus efeitos, de forma a mitigar o problema (Bertoni \& Lombardi Neto 2008).

1. Trabalho recebido em jan./2014 e aceito para publicação em jan./2015 (http://dx.doi.org/10.1590/1983-40632015v4528029).

2. Universidade Federal do Acre (UFAC), Centro de Ciências Biológicas e da Natureza, Departamento de Produção Vegetal, Rio Branco, AC, Brasil.E-mail: danimique@yahoo.com.br.

3. Universidade Estadual Paulista "Júlio de Mesquita Filho" (Unesp), Faculdade de Ciências Agrárias e Veterinárias, Departamento de Solos e Adubos, Jaboticabal, SP, Brasil.E-mails: emg_carnero@hotmail.com, crbueno@unesp.br. 
O processo erosivo superficial foi modelado na década de 1970, por Wischmeier \& Smith (1978), resultando na Equação Universal de Perda de Solo (USLE). Por meio desse modelo é possível estimar as perdas de solo e identificar os fatores que exercem os maiores efeitos nesse processo de degradação ambiental. Segundo Barreto et al. (2008), em estudos brasileiros de perda acelerada de solo, há predominância no enfoque da erosão a partir de uma perspectiva agrícola e grande ênfase na pesquisa dos fatores do modelo USLE de estimativa de erosão, principalmente por ser um modelo de fácil estimativa de parâmetros e aplicação.

Dentre os fatores da USLE, o relevo é apontado como um dos principais agentes do processo erosivo, por direcionar o fluxo de água superficial, condicionando a perda de solo (Sanchez et al. 2009, Leão et al. 2010, Santos et al. 2011). O estudo das formas do relevo que influenciam o escoamento da água sobre a paisagem é fundamental para o entendimento e a quantificação da erosão e da variabilidade dos atributos dos solos (Sanchez et al. 2009).

A quantificação da erosão, associada às formas de paisagem, tem apresentado subsídios para a determinação de zonas específicas de manejo (Barbieri et al. 2008). No entanto, quando os fatores naturais, erosividade da chuva, erodibilidade do solo e o relevo são constantes e de baixa magnitude, o fator antrópico passa a desempenhar papel importante no processo erosivo (Weill \& Sparovek 2008). A ocupação e manejo acarretam alterações físicas e químicas do solo, influenciando, inclusive, na variabilidade espacial desses atributos (Vieira 2000, Vieira et al. 2011).

Segundo Bueno \& Stein (2004), uma vez compreendida a paisagem natural, de acordo com os fatores atuantes nos processos de erosão, a tendência de ocupação dos solos é a de utilização de áreas onde os limites potenciais são respeitados, resultando na adequação das práticas de uso e zonas de manejo, minimizando, assim, a degradação ambiental.

Zonas de manejo são áreas passíveis de receber as mesmas práticas agronômicas, por apresentarem potencial de resposta similar e estarem sujeitas aos mesmos riscos e limitações do uso agrícola. $\mathrm{O}$ intuito principal da definição dessas zonas é aumentar a produtividade e adequar o manejo às especificidades ambientais de cada subárea (Sanchez et al. 2009). Com o estudo da variabilidade espacial de atributos químicos e texturais do solo, há o desenvolvimento de subsídios suficientes para a definição de zonas homogêneas de manejo (Barbieri et al. 2008, Santos et al. 2011).

Assim, este trabalho objetivou caracterizar o solo química e fisicamente, bem como verificar possíveis zonas de manejo, por meio da variabilidade espacial das estimativas de perda de solo, e atributos limitantes ao desenvolvimento das culturas na área estudada, determinando os fatores de maior atuação no processo erosivo.

\section{MATERIAL E MÉTODOS}

A área de estudo, com cerca de 130 ha, está localizada no município de Colômbia (SP), no fuso $22 \mathrm{~K}$, entre as coordenadas centrais $737950 \mathrm{E}$ e 7751000S (UTM Córrego Alegre, Sul) (Figura 1). Com declividade máxima de $4,5 \%$, a área é cultivada com cana-de-açúcar e citros e situa-se em região com clima Aw, tropical, com estação seca de inverno, segundo Köppen. A altitude média é de 540 m, com predominância de Latossolo Vermelho-Amarelo distrófico (Embrapa 2006), oriundo de arenitos da Formação Adamantina, Grupo Bauru. O relevo de entorno é classificado como suave ondulado (IPT 1981).

Para análise dos atributos granulométricos e químicos do solo, foram amostrados 129 pontos georreferenciados nos entrenós de uma grade regular de $100 \mathrm{~m}$, nas camadas de $0-0,20 \mathrm{~m}$ e $0,40-0,60 \mathrm{~m}$, totalizando 258 amostras, entre junho e julho de 2009.

A análise granulométrica das amostras foi realizada pelo método da pipeta, por meio da dispersão de $\mathrm{NaOH} 0,1 \mathrm{~mol} \mathrm{~L}^{-1}$, e agitação lenta por 16 horas, em agitador rotatório tipo Wagner, a $50 \mathrm{rpm}$ (Day 1965). As frações das partículas maiores de solo foram separadas por peneiramento e as frações menores por sedimentação, segundo a lei de Stokes. A fração

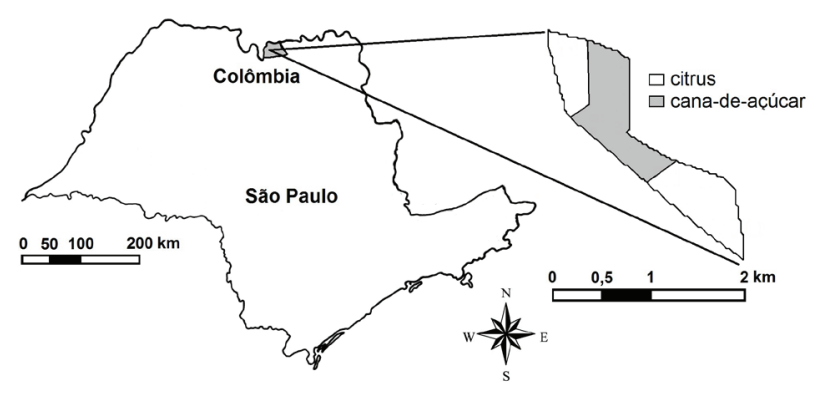

Figura 1. Localização da área de estudo e distribuição das culturas (Colômbia, SP, 2009). 
areia foi decomposta segundo classificação americana (Santos et al. 2005), nas seguintes classes: areia muito grossa $(2,0-1,0 \mathrm{~mm})$, areia grossa $(1,0-0,5 \mathrm{~mm})$, areia média $(0,5-0,25 \mathrm{~mm})$, areia fina $(0,25-0,105 \mathrm{~mm}) \mathrm{e}$ areia muito fina $(0,105-0,053 \mathrm{~mm})$. O silte foi determinado por diferença do somatório das frações areia e argila e a matéria orgânica pelo método colorimétrico, com oxidação pela solução de dicromato de sódio e leitura pelo colorímetro (Cantarella et al. 2001). O $\mathrm{pH}$ foi determinado potenciometricamente, por meio da relação 1:2,5 de solo em $\mathrm{CaCl}_{2}$; a acidez potencial $(\mathrm{H}+\mathrm{Al})$ extraída com $\mathrm{Ca}(\mathrm{OAc})_{2}$ e quantificada por titulometria; e o potássio $(\mathrm{K})$, cálcio $(\mathrm{Ca})$ e magnésio $(\mathrm{Mg})$ determinados utilizando-se o método da resina trocadora de íons (Raij et al. 2001).

Os dados granulométricos e de matéria orgânica foram utilizados para o cálculo da Equação Universal de Perda de Solo (USLE), segundo Wischmeier \& Smith (1978): A = R K L S C P, em que $\mathrm{A}=$ estimativa da perda de solo, em $\mathrm{Mg} \mathrm{ha}^{-1} \mathrm{ano}^{-1} ; \mathrm{R}=$ fator erosividade da chuva, em Mj mm ha ${ }^{-1} \mathrm{~h}^{-1}$, obtido pelo programa NetErosividade (Moreira et al. 2006); $\mathrm{K}=$ fator erodibilidade do solo, em $\mathrm{Mg} \mathrm{h} \mathrm{Mj}{ }^{-1} \mathrm{~mm}^{-1}$, determinado segundo Denardin (1990); LS = fator topográfico (adimensional), segundo Bertoni \& Lombardi Neto (2008); C = fator uso e manejo (adimensional), segundo Bertoni \& Lombardi Neto (2008); $\mathrm{P}=$ fator práticas conservacionistas (adimensional), calculado segundo Lagrotti (2000).

$O$ potencial natural de erosão (PNE), em $\mathrm{Mg} \mathrm{ha}^{-1} \mathrm{ano}^{-1}$, que leva em conta apenas os fatores naturais de perda de solo, foi determinando pela multiplicação dos fatores naturais R, K e LS. O risco de erosão (RE), adimensional, foi obtido pela razão entre a perda de solo estimada (A) pela perda tolerável para Latossolos, que, para o Estado de São Paulo, é de $12 \mathrm{Mg} \mathrm{ha}^{-1}$ ano $^{-1}$ (Bertoni \& Lombardi Neto 2008).

A expectativa de erosão (EE), adimensional, foi quantificada pela diferença entre o fator antrópico (CP) calculado e o tolerável (Bueno \& Stein 2004). Segundo Bueno \& Stein (2004), a expectativa de erosão representa a susceptibilidade da área à erosão, em função dos fatores de ocupação, sendo a determinação do fator antrópico tolerável expressa pela relação de perda do solo (A) pelo potencial natural de erosão (PNE). Nesse caso, as discordâncias negativas ou nulas entre o fator antrópico calculado e o tolerável mostram ocupação compatível com a capacidade de uso do solo, enquanto as discordâncias positivas indicam uso inadequado, com riscos de perda de solo. A classificação adotada para a perda de solo, potencial natural de erosão e risco de erosão foi a proposta por Lagrotti (2000) (Tabela 1).

A estatística descritiva dos dados foi realizada pela determinação das medidas de tendência central, média e mediana, e de dispersão, desvio padrão e coeficiente de variação, além da análise de normalidade de dados pelo teste de Kolmogorov-Smirnov, a $5 \%$, para os atributos químicos, granulometria do solo, estimativas de perda de solo, potencial natural de erosão, risco de erosão, expectativa de erosão e fator antrópico. Os coeficientes de variação foram classificados segundo Dalchiavon et al. (2012).

Para a análise da variabilidade espacial da perda de solo, potencial natural de erosão, risco de erosão, expectativa de erosão, fator antrópico e $\mathrm{pH}$, para as camadas de 0-0,20 m e 0,40-0,60 m, utilizou-se o programa GS+ 7.0 (GDS 2004), pelo cálculo do semivariograma, com base nos pressupostos de estacionaridade da hipótese intrínseca (Vieira 2000). Os ajustes dos semivariogramas, relacionando acima de 50 pares por classe de distância, vizinhança de 16 pontos e em função de seus modelos, foram efetuados considerando-se a menor soma de quadrados do resíduo, maior coeficiente de determinação, melhor desempenho da validação cruzada e maior avaliador da dependência espacial (ADE).

$\mathrm{O}$ efeito pepita $\left(\mathrm{C}_{0}\right)$ permite verificar o grau de descontinuidade da variação dos dados a distâncias menores que as amostradas e, quanto maior a diferença do efeito pepita, em relação ao patamar, maior é a confiança na estimativa (Vieira 2000). Dessa forma, o avaliador de dependência espacial, que relaciona a variância estrutural $(\mathrm{C})$ com o patamar $\left(\mathrm{C}+\mathrm{C}_{0}\right)$, avalia o grau de dependência entre os pontos amostrados da variável (GDS 2004): $\mathrm{ADE}=\left[\mathrm{C} /\left(\mathrm{C}+\mathrm{C}_{0}\right)\right] \times 100$, em que $\mathrm{ADE}=$ avaliador da dependência espacial; $\mathrm{C}=$ variância estrutural; e $\mathrm{C}+\mathrm{C}_{0}=$ patamar.

Tabela 1. Classificação da perda de solo (A), potencial natural de erosão (PNE) e risco de erosão (RE) (Colômbia, SP, 2009).

\begin{tabular}{|c|c|c|c|}
\hline & A & PNE & RE \\
\hline & \multicolumn{2}{|c|}{$-\mathrm{Mg} \mathrm{ha}^{-1} \mathrm{ano}^{-1}$} & adimensional \\
\hline Muito baixa & $<10$ & $<250$ & $<1$ \\
\hline Baixa & $10-20$ & $250-500$ & $1-2$ \\
\hline Moderada & $20-50$ & $500-750$ & $2-5$ \\
\hline Alta & $50-100$ & $750-1000$ & $5-10$ \\
\hline Muito alta & $>100$ & $>1000$ & $>10$ \\
\hline
\end{tabular}


A interpretação para o ADE seguiu a proposta de Dalchiavon et al. (2012), que considera a seguinte classificação do ADE: $<20 \%$ = variável espacial de muito baixa dependência; $20 \% \leq \mathrm{ADE}<40 \%=$ baixa dependência; $40 \% \leq \mathrm{ADE}<60 \%=$ média dependência; $60 \% \leq \mathrm{ADE}<80 \%=$ alta dependência; e $80 \% \leq \mathrm{ADE}<100 \%=$ muito alta dependência. O delineamento dos mapas de isolinhas, incluindo o mapa planialtimétrico e o de vetor de escoamento superficial, bem como os cálculos das áreas para cada variável, foram realizados com o auxílio do programa Surfer 8.0 (Golden Software 1997).

\section{RESULTADOS E DISCUSSÃO}

Os valores médios para a camada de $0-0,20 \mathrm{~m}$ indicam solo de textura franco-argilo-arenosa, com média de argila acima de $200 \mathrm{~g} \mathrm{~kg}^{-1}$ de solo e areia total acima de $700 \mathrm{~g} \mathrm{~kg}^{-1}$ (Tabela 2). O mesmo foi observado para a camada de $0,40-0,60 \mathrm{~m}$, o que está de acordo com a textura da classe de Latossolos da região centro-oeste paulista e sul de Minas Gerais (Sanchez et al. 2009, Leão et al. 2010, Silva et al. 2010).

A argila aumentou em profundidade, porém, de forma pouco acentuada, característica dessa classe de solo (Embrapa 2006). O teor de silte foi baixo e variou pouco em profundidade. Segundo Amaro Filho et al. (2008), seu comportamento pode trazer consequências desfavoráveis, dependendo de sua distribuição, pois partículas dessa fração possuem instabilidade natural e não permitem a infiltração de água e ar no solo, formando uma crosta superficial e impedindo a emergência de plântulas.

Os teores das areias grossa, média e fina diminuiram em profundidade. Já a areia muito fina aumentou, o que pode evidenciar o transporte seletivo ao longo do perfil, uma vez que a área possui baixa declividade. De acordo com Bertoni \& Lombardi Neto (2008), além da gênese, a declividade tem grande influência na distribuição das partículas do solo, devido ao arraste, caracterizando a erosão preferencial segundo as pedoformas, o que torna o tipo de cobertura do solo um aspecto essencial para a conservação.

Quanto aos atributos químicos, o teor de matéria orgânica decresceu em profundidade, de forma oposta à acidez, que aumentou, indicando acidez potencial com alto grau de heterogeneidade, ao longo da área. O gradiente de acidez, ao longo do perfil, ocorre, provavelmente, pela facilidade com que a matéria orgânica complexa o $\mathrm{Al}^{+}$, principalmente por meio dos grupos carboxila e hidroxila, em que os ácidos orgânicos são estabilizados por esse íon, reduzindo sua atividade no solo (Alleoni \& Melo 2009). A acidez foi considerada alta em profundidade, os teores de $\mathrm{Ca}$ e Mg médios nas duas camadas estudadas e os teores de $\mathrm{K}$ médio para a primeira camada e baixo para a segunda (Raij et al. 2001).

Cálcio e magnésio são exigidos em maior quantidade pelas plantas cítricas e, segundo Auler et al. (2011), sua correlação é positiva com a produção.

Tabela 2. Estatística descritiva dos atributos granulométricos e químicos do solo (Colômbia, SP, 2009).

\begin{tabular}{|c|c|c|c|c|c|c|c|c|c|c|c|c|}
\hline \multirow{2}{*}{ Variáveis } & $\mathrm{AG}$ & $\mathrm{AM}$ & $\mathrm{AF}$ & AMF & Silte & Argila & $\mathrm{K}$ & $\mathrm{Ca}$ & $\mathrm{Mg}$ & $\mathrm{MO}$ & $\mathrm{pH}$ & $\mathrm{H}+\mathrm{Al}$ \\
\hline & & & $-\mathrm{g} \mathrm{kg}$ & 1 & & + & \multicolumn{3}{|c|}{$-\mathrm{mmol}_{\mathrm{c}} \mathrm{dm}^{-3}-$} & $\mathrm{g} \mathrm{dm}^{-3}$ & $\mathrm{CaCl}_{2}$ & $\mathrm{mmol}_{\mathrm{c}} \mathrm{dm}^{-3}$ \\
\hline & \multicolumn{12}{|c|}{ Camada $0-0,20 \mathrm{~m}$} \\
\hline Média & 9,00 & 160,00 & 487,00 & 118,00 & 22,00 & 203,00 & 1,10 & 40,30 & 16,60 & 15,10 & 5,60 & 17,80 \\
\hline Mediana & 6,00 & 162,00 & 491,00 & 118,00 & 21,00 & 195,00 & 0,90 & 39,00 & 17,00 & 15,00 & 5,80 & 15,00 \\
\hline DP & 9,00 & 46,80 & 63,70 & 24,40 & 11,40 & 35,20 & 0,60 & 16,90 & 7,80 & 3,66 & 0,50 & 7,85 \\
\hline Assimetria & 1,41 & 0,02 & 0,13 & $-0,09$ & 0,85 & 0,14 & 1,28 & 0,88 & 0,68 & 0,39 & $-0,82$ & 1,48 \\
\hline Curtose & 2,90 & $0,25 *$ & $0,19 *$ & $0,71 *$ & 0,50 & $-0,34 *$ & 1,47 & 1,89 & $1,06^{*}$ & $-0,17 *$ & 0,21 & 1,64 \\
\hline \multirow[t]{2}{*}{ CV (\%) } & 97,73 & 29,25 & 13,08 & 20,68 & 50,56 & 17,39 & 55,55 & 41,99 & 46,91 & 24,27 & 8,80 & 44,06 \\
\hline & \multicolumn{12}{|c|}{ Camada $0,40-0,60 \mathrm{~m}$} \\
\hline Média & 7,00 & 145,00 & 461,00 & 127,00 & 21,00 & 239,00 & 0,70 & 13,60 & 5,50 & 8,80 & 4,90 & 22,90 \\
\hline Mediana & 3,00 & 139,00 & 469,00 & 126,00 & 19,00 & 233,00 & 0,40 & 11,00 & 5,00 & 8,00 & 5,00 & 20,00 \\
\hline DP & 9,80 & 46,40 & 58,40 & 46,40 & 8,70 & 37,70 & 0,60 & 8,30 & 3,70 & 2,64 & 0,57 & 9,00 \\
\hline Assimetria & 3,33 & 0,23 & $-0,11$ & $-0,06$ & 0,73 & 0,43 & 1,73 & 2,12 & 2,10 & 0,99 & 0,04 & 0,98 \\
\hline Curtose & 19,58 & $0,45^{*}$ & $-0,37 *$ & $0,69 *$ & 0,42 & $-0,54$ & 2,20 & 9,10 & 7,16 & $0,99 *$ & $-0,85^{*}$ & 0,53 \\
\hline CV (\%) & 140,85 & 32,00 & 12,68 & 36,53 & 41,61 & 15,75 & 85,70 & 61,00 & 67,30 & 29,98 & 11,49 & 39,43 \\
\hline
\end{tabular}

AG: areia grossa; AM: areia média; AF: areia fina; AMF: areia muito fina; K: potássio; Ca: cálcio; Mg: magnésio; MO: matéria orgânica; pH: potencial hidrogeniônico; H+Al: acidez potencial; DP: desvio padrão; CV: coeficiente de variação. * Distribuição normal pelo teste de Kolmogorov-Smirnov, a 5 \%. 
Já a acidez, de acordo com Caione et al. (2013), é um fator restritivo ao desenvolvimento radicular da cana-de-açúcar e esse pode ser um atributo limitante ao desenvolvimento das culturas, devendo, assim, ser analisado espacialmente.

As frações areia média, areia fina, areia muito fina e a matéria orgânica apresentaram comportamento normal, para ambas as camadas, com coeficiente de variação $(\mathrm{CV})$ médio para areia fina e alto para as demais (Dalchiavon et al. 2012). A argila e o magnésio apresentaram comportamento normal para a camada de $0-0,20 \mathrm{~m}$, com CV médio e muito alto, respectivamente. Para a camada de $0,40-0,60 \mathrm{~m}, \mathrm{o} \mathrm{pH}$ apresentou comportamento normal, com $\mathrm{CV}$ médio. $\mathrm{O} \mathrm{pH}$ da menor profundidade e a argila da maior profundidade apresentaram comportamento com tendência à normalidade, devido à proximidade da média e mediana (Leão et al. 2010), com CV baixo e médio, respectivamente.

As variáveis químicas potássio, cálcio e acidez potencial e as granulométricas areia grossa e silte apresentaram altos $\mathrm{CV}$, indicando grande variação na área. Apesar da condição de estabilidade atribuída a essa classe de solo, oriunda de seu grau avançado de intemperismo, Sanchez et al. (2009) e Leão et al. (2010) também observaram grande variabilidade em Latossolos, principalmente nas camadas mais superficiais. Essas camadas são as que sofrem maiores alterações, principalmente pela ação antrópica, o que acarreta baixo grau de homogeneidade de suas características químicas, principalmente pelo aporte de nutrientes, e físicas, pelo uso de maquinários agrícolas (Montanari et al. 2008, Dalchiavon et al. 2012).

A perda de solo média foi de $55,26 \mathrm{Mg} \mathrm{ha}^{-1} \mathrm{ano}^{-1}$, o potencial natural de erosão de $321,12 \mathrm{Mg} \mathrm{ha}^{-1}$ ano $^{-1}$ e o risco de erosão de 4,6 (Tabela 3). Segundo Bertoni \& Lombardi Neto (2008), a tolerância de perda de solo para Latossolos do Estado de São Paulo é alta, podendo variar em 4,3-15 $\mathrm{Mg} \mathrm{ha}^{-1}$ ano $^{-1}$. Essa variação ocorre em virtude de sua profundidade e da pequena diferença textural dos horizontes, com boa drenagem interna, aumentando, assim, os limites de tolerância. No entanto, o valor médio observado para a área é cerca de quatro vezes maior que o tolerado, o que acarreta estado de atenção para o uso e manejo da área.

A taxa de perda de solo depende da facilidade de desprendimento e transporte de partículas, sendo função principalmente da textura e matéria orgânica, além da estrutura e permeabilidade (Bertoni \& Lombardi Neto 2008). No entanto, devido à baixa declividade do terreno, a perda acentuada de solo, provavelmente, está ligada ao manejo inadequado e ao tipo de cobertura (Bueno \& Stein 2004).

A perda de solo, potencial natural e risco de erosão apresentaram comportamento normal, no entanto, com CV muito alto, indicando alta heterogeneidade dessas variáveis na área. Segundo Landim (2006) e Vieira (2000), na análise geoestatística, o ideal é que os semivariogramas apresentem patamares bem definidos e a distribuição dos dados não tenha caudas muito alongadas, o que poderia comprometer as estimativas da krigagem.

Os valores médios da perda de solo, potencial natural e risco de erosão foram maiores que os observados por Campos et al. (2008), para Latossolos da região de Pereira Barreto (SP). Já Silva et al. (2010) observaram menor perda de solo para Latossolos do centro e nordeste de Minas Gerais e Sanchez et al. (2009) maiores CV para perda de solo e risco de erosão e menor valor para potencial natural de erosão em Catanduva (SP). Esses autores atribuíram a perda de solo ao relevo, que condiciona a erosão por meio do direcionamento do fluxo de água pelo terreno (Barbieri et al. 2008).

Os modelos ajustados dos semivariogramas, com os respectivos parâmetros, encontram-se na Tabela 4. Para a maior parte das variáveis, o modelo ajustado foi o gaussiano, pois capta pequenas variabilidades a menores distâncias (Landim 2006), exceto

Tabela 3. Estatística descritiva de perda de solo (Colômbia, SP, 2009).

\begin{tabular}{lrrrrrr}
\hline \multicolumn{1}{c}{ Variável } & \multicolumn{1}{c}{ Média } & Mediana & Desvio padrão & Assimetria & Curtose & $\mathrm{CV}$ \\
\hline $\mathrm{A}\left(\mathrm{Mg} \mathrm{ha}^{-1}\right.$ ano $\left.^{-1}\right)$ & 55,260 & 55,040 & 28,040 & 0,025 & $-0,90^{*}$ & 50,74 \\
$\mathrm{PNE}\left(\mathrm{Mg} \mathrm{ha}^{-1}\right.$ ano $\left.^{-1}\right)$ & 321,120 & 318,940 & 164,500 & 0,006 & $-0,89 *$ & 50,23 \\
$\mathrm{RE}$ (adimensional) & 4,600 & 4,590 & 2,340 & 0,026 & $-0,90 *$ & 50,74 \\
$\mathrm{CP}$ (adimensional) & 0,174 & 0,173 & 0,007 & 2,910 & 15,40 & 4,12 \\
$\mathrm{EE}$ (adimensional) & 0,104 & 0,132 & 0,009 & $-4,780$ & 28,27 & 96,86 \\
\hline
\end{tabular}

A: perda de solo; PNE: potencial natural de erosão; RE: risco de erosão; CP: fator antrópico; EE: expectativa de erosão; CV: coeficiente de variação. * Distribuição normal pelo teste de Kolmogorov-Smirnov, a $5 \%$. 
Tabela 4. Modelos e parâmetros dos semivariogramas ajustados para a perda de solo (Colômbia, SP, 2009).

\begin{tabular}{|c|c|c|c|c|c|c|c|c|c|c|}
\hline & Modelo & $\mathrm{C}_{0}$ & $\mathrm{C}+\mathrm{C}_{0}$ & $\mathrm{a}$ & ADE & $\mathrm{S} \mathrm{r}^{2}$ & SQR & Coef R & EP & $\mathrm{VCr}^{2}$ \\
\hline $\begin{array}{l}\text { pH } 0,00-0,20 \mathrm{~m} \\
\mathrm{pH} 0,40-0,60 \mathrm{~m}\end{array}$ & Esférico & 0,086 & 0,2776 & 842,00 & $\begin{aligned} & 69,1 \\
& \text { efeito } p\end{aligned}$ & $\begin{array}{l}0,948 \\
\text { ita puro }\end{array}$ & 0,0021 & 1,016 & 0,097 & 0,465 \\
\hline PNE & Gaussiano & 3560 & 24610 & 564,64 & 85,5 & 0,997 & 1031736 & 1,016 & 0,041 & 0,826 \\
\hline A & Gaussiano & 104 & 690,4 & 568,11 & 84,9 & 0,999 & 377 & 1,021 & 0,041 & 0,830 \\
\hline RE & Gaussiano & 0,75 & 4,802 & 573,31 & 84,4 & 0,999 & 0,0167 & 1,024 & 0,041 & 0,830 \\
\hline $\mathrm{CP}$ & Esférico & $4,0 \mathrm{E}-06$ & $6,7 \mathrm{E}-05$ & 623,00 & 93,9 & 0,976 & $6,12 \mathrm{E}-11$ & 0,841 & 0,088 & 0,419 \\
\hline $\mathrm{EE}$ & Gaussiano & $1,8 \mathrm{E}-03$ & $1,2 \mathrm{E}-02$ & 916,25 & 84,9 & 0,984 & 1,9E-06 & 1,002 & 0,073 & 0,595 \\
\hline
\end{tabular}

A: perda de solo; PNE: potencial natural de erosão; RE: risco de erosão; $\mathrm{CP}$ : fator antrópico; EE: expectativa de erosão; $\mathrm{C}_{0}$ : efeito pepita; $\mathrm{C}+\mathrm{C}_{0}$ : patamar; a: alcance,

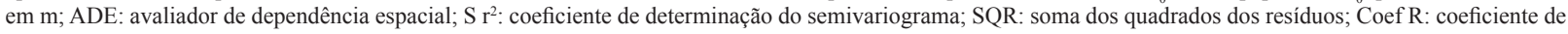
regressão; EP: erro padrão da validação cruzada; $\mathrm{VC}$ r²: coeficiente de determinação da validação cruzada.

para o fator antrópico e o $\mathrm{pH}$, na primeira camada, com ajuste do modelo esférico, que, de acordo com Landim (2006), é o mais utilizado. O pH, na camada de $0,40-0,60 \mathrm{~m}$, apresentou efeito pepita puro, o que impediu o ajuste do semivariograma.

O alcance da perda de solo, potencial natural e risco de erosão variaram pouco, com valores de $564,6-573,3 \mathrm{~m}$, indicando que os pontos dentro dessas distâncias são semelhantes. Quanto maior a distância, maior a variância e a independência entre os pontos (Vieira et al. 2011). Já para o fator antrópico, expectativa de erosão e $\mathrm{pH}$, os alcances foram de 623-916,5 m.

O coeficiente de determinação foi alto para todas as variáveis (acima de $94 \%$ ), assim como o coeficiente de validação cruzada (acima de 82 \%), exceto para o fator antrópico, expectativa de erosão e $\mathrm{pH}$, que apresentam maior variação, pois consideram apenas as práticas antrópicas, isto é, manejo, incluindo o condicionamento do $\mathrm{pH}$, e as culturas, que variam ao longo da área. O mesmo foi observado por Weill \& Sparovek (2008), os quais constataram que os fatores antrópicos foram responsáveis pela ordem de grandeza da estimativa da perda de solo, principalmente em áreas com culturas anuais, devido ao manejo mais intenso.

As variáveis naturais ou intrínsecas, como tipo de solo e relevo, que não são consideradas nos fatores antrópicos, apresentam-se mais homogêneas na área, principalmente pelo predomínio de apenas uma classe de solo, em uma declividade relativamente baixa. Para todas as variáveis, houve dependência espacial muito alta, acima de $84 \%$, exceto para $\mathrm{pH}$, com dependência alta, indicando a continuidade do fenômeno observado (Vieira et al. 2011).

De modo geral, as perdas médias concentram-se na parte central da área, onde há o cultivo de cana-de-açúcar (Figura 1), provavelmente devido à colheita da cultura, que revolve o solo na reforma e o deixa descoberto anualmente. Apesar de grande parte da área se mostrar linear, a maior perda de solo e de potencial natural de erosão estão concentrados na porção mais elevada do terreno (Figura 2), no plantio de citrus, onde existe ligeira convexidade. Mesmo com cobertura perene, essa area é afetada de forma direta e intensa pela erosão, uma vez que tal pedoforma contribui para a exposiçao do solo e, em associação com os fatores antrópicos, aumenta o risco do processo erosivo (Sanchez et al. 2009).

Independentemente da cota do terreno, o $\mathrm{pH}$ mais ácido aparece nas áreas de cultivo de citrus (Figura 3), onde a área de cota mais elevada é mais convexa e expõe a pedoforma e a superficie do solo à precipitação e consequente perda pelo processo erosivo, e na menor cota, com área mais côncava e acúmulo de sedimentos. Auler et al. (2011) observaram valores de $\mathrm{pH}$ mais ácidos para Latossolo no

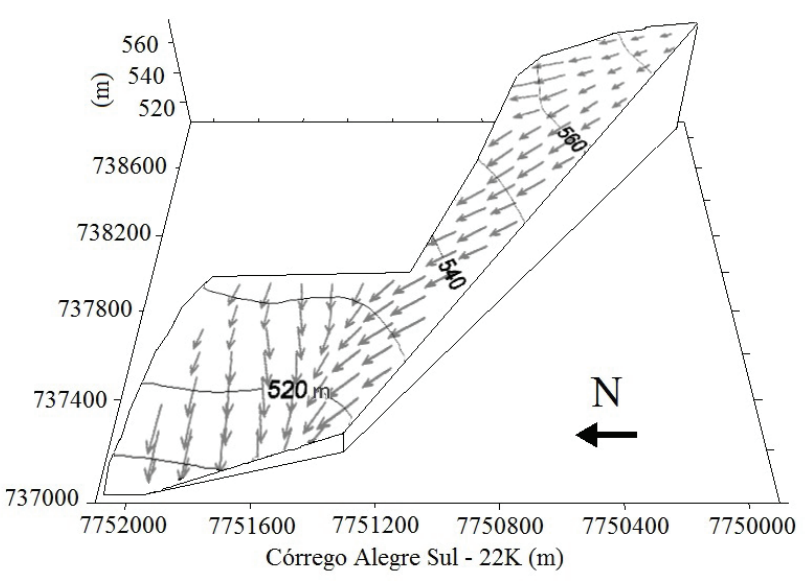

Figura 2. Mapa planialtimétrico, com vetores de escoamento superficial de água (Colômbia, SP, 2009). 


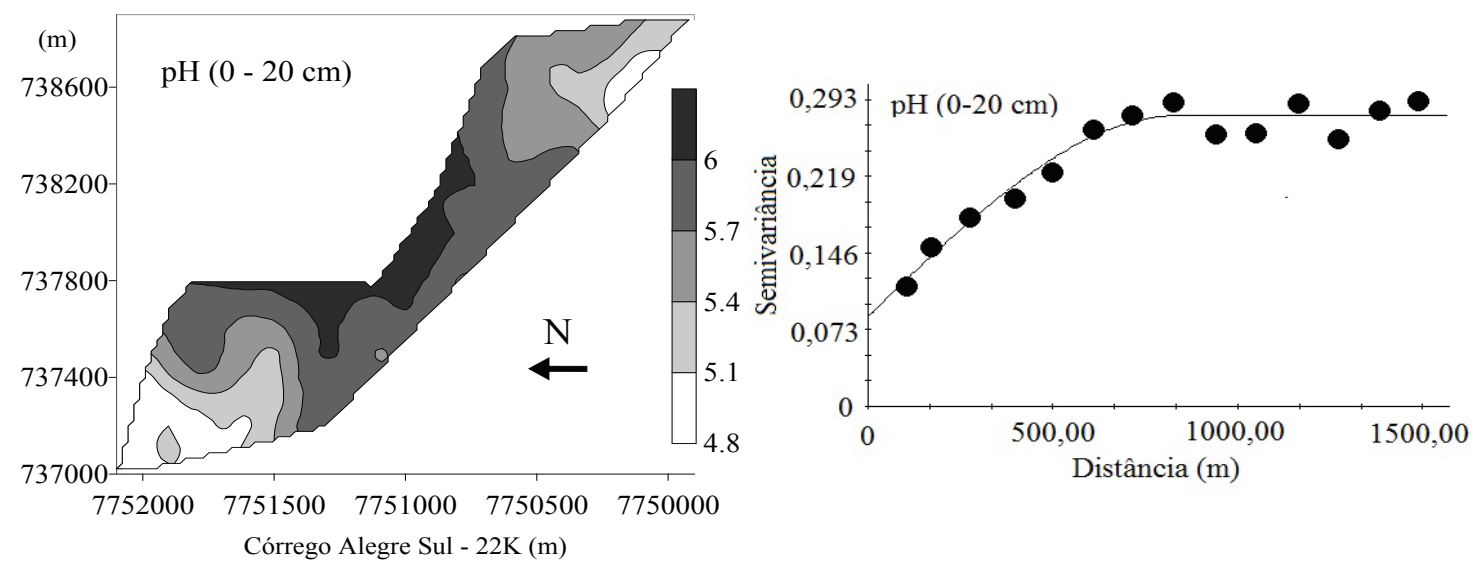

Figura 3. Mapa de isolinhas e semivariograma de $\mathrm{pH}$ da camada de 0-0,20 m (Colômbia, SP, 2009).

noroeste do Paraná, que, aparentemente, não foram baixos o suficiente para comprometer o desenvolvimento do citrus. No entanto, os autores salientam que a prática da calagem favorece o crescimento das raízes e aumenta a disponibilidade de outros nutrientes. Tal prática deve ser realizada principalmente nas áreas determinadas pelo mapa, indicando zonas de manejo para acidez relacionadas ao tipo de superfície do solo.

Segundo Vieira et al. (2011), a varibilidade dos atributos do solo é influenciada pelo histórico de manejo, gerando cenários positivos ou negativos para as culturas. Além disso, Montanari et al. (2008) afirmam que trabalhos regionais indicam que as formas lineares condicionam menor variabilidade espacial de atributos químicos, em relação às formas côncavas e convexas.

Diversos trabalhos indicam que a erosão dos solos aumenta das pedoformas côncavas para as convexas, passando pela linear, que possui maior estabilidade (Barbieri et al. 2008, Campos et al. 2008, Sanchez et al. 2009), o que também pode ser observado na parte de menor cota do terreno, com cultivo de citrus, onde o $\mathrm{pH}$ é mais ácido e há o delineamento de uma superfície mais côncava, com baixos índices de perdas de solo e risco de erosão (Figuras 4a, 4b e 4c).

Segundo Sanchez et al. (2009), as pedoformas côncavas proporcionam maior variabilidade espacial, uma vez que há tendência de acúmulo de sedimentos nesses locais. Por outro lado, as Figuras $5 \mathrm{a}$ e $5 \mathrm{~b}$ mostram que o fator antrópico de perda de solo, juntamente com o risco de erosão, são maiores exatamente onde o fator natural de erosão é baixo.

Na parte de menor cota do terreno, onde há a pedoforma côncava (Figura 2), o manejo é inadequado e o pH ácido, com risco de erosão, mostrando discrepância entre manejo e tolerância de perda de solo, o que reflete em maior possibilidade de erosão (Bueno \& Stein 2004). A porcentagem de área classificada para cada variável, segundo os níveis de perda de solo, pode ser observada na Tabela 5.

A perda de solo está entre moderada e alta, em mais de $90 \%$ da área. Essa alta porcentagem ocorre, principalmente, devido ao fator antrópico, segundo o modelo de Wischmeier \& Smith (1978), uma vez que os fatores naturais de perda são minimizados pela baixa declividade, fazendo com que $91 \%$ da

Tabela 5. Classificação da perda de solo (A), potencial natural de erosão (PNE) e risco de erosão (RE) (Colômbia, SP, 2009).

\begin{tabular}{lccccccccc}
\hline & $\mathrm{A}$ & $\mathrm{A}$ & $\mathrm{A}$ & $\mathrm{PNE}$ & $\mathrm{PNE}$ & $\mathrm{PNE}$ & $\mathrm{RE}$ & $\mathrm{RE}$ & $\mathrm{RE}$ \\
\hline & $\mathrm{Mg} \mathrm{ha}^{-1} \mathrm{ano}^{-1}$ & \multicolumn{1}{c}{$\mathrm{ha}$} & \multicolumn{1}{c}{$\%$} & $\mathrm{Mg} \mathrm{ha}^{-1} \mathrm{ano}^{-1}$ & \multicolumn{1}{c}{ ha } & \multicolumn{1}{c}{$\%$} & adimensional & \multicolumn{1}{c}{ ha } & $\%$ \\
\hline Muito baixa & $<10$ & 2,52 & 1,9 & $<250$ & 42,34 & 32,4 & $<1$ & 3,86 & 2,96 \\
Baixa & $10-20$ & 8,75 & 6,7 & $250-500$ & 77,32 & 59,2 & $1-2$ & 11,15 & 8,54 \\
Moderada & $20-50$ & 42,14 & 32,3 & $500-750$ & 10,87 & 8,3 & $2-5$ & 115,52 & 88,50 \\
Alta & $50-100$ & 75,69 & 58,0 & $750-1000$ & 0,00 & 0,0 & $5-10$ & 0,00 & 0,00 \\
Muito alta & $>100$ & 1,43 & 1,1 & $>1000$ & 0,00 & 0,0 & $>10$ & 0,00 & 0,00 \\
\hline
\end{tabular}



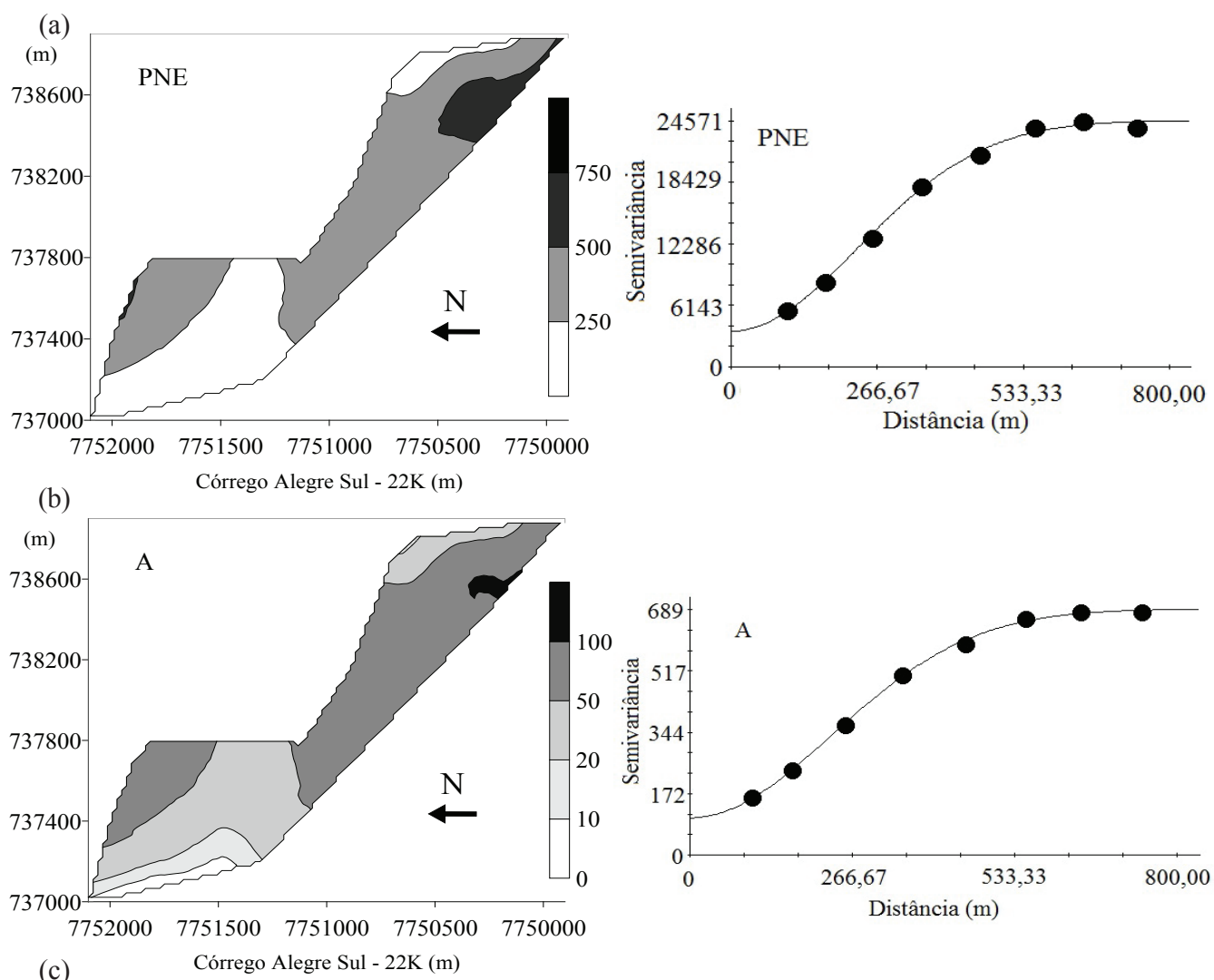

(c)
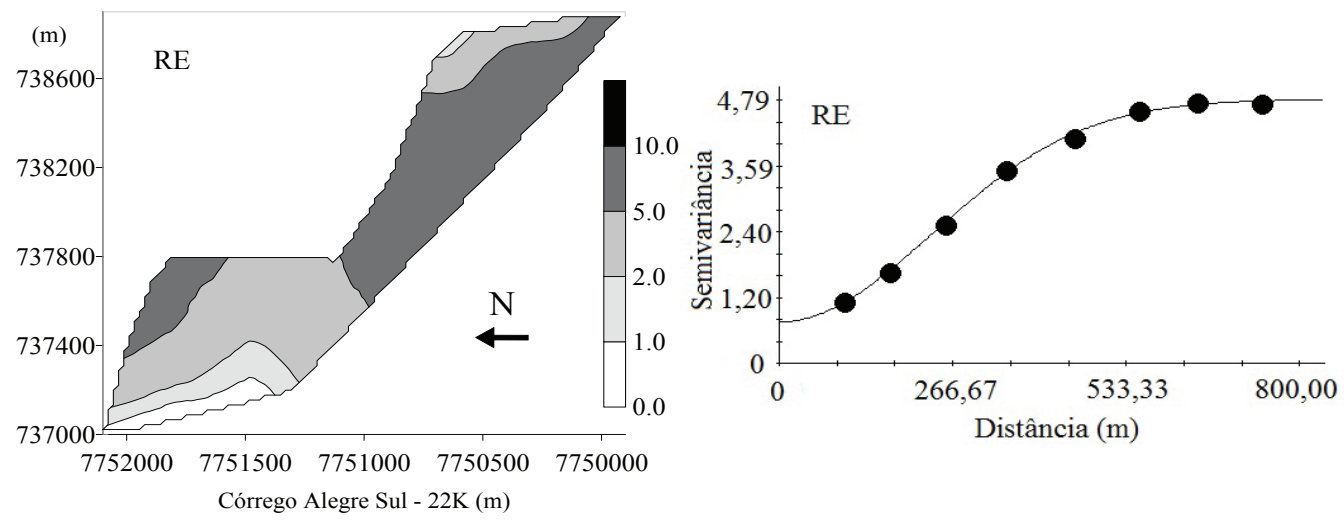

Figura 4. Mapas de isolinhas e semivariogramas: (a) potencial natural de erosão (PNE), em $\mathrm{Mg} \mathrm{ha}^{-1} \mathrm{ano}^{-1}$; (b) perda de solo (A), em $\mathrm{Mg} \mathrm{ha}^{-1} \mathrm{ano}^{-1}$; e (c) risco de erosão (RE), adimensional (Colômbia, SP, 2009).

área apresentem potencial natural de erosão com valores de baixo a muito baixo. Também é importante destacar que a área é composta por uma única classe de solo, mantendo o mesmo padrão da erodibilidade. Já o risco de erosão é moderado em mais de $88 \%$ da área, devido à cobertura e manejo do solo (Tabela 5). Esses resultados indicam que os fatores antrópicos, isto é, tratos culturais e ocupação do solo, condicionam sua perda (Bueno \& Stein 2004).

O padrão de distribuição de RE e CP é semelhante ao longo da área, a qual possui cultivo de la- ranja com algumas regiões necessitando de reforma. A área com menor cota possui potencial mínimo de erosão pelo acúmulo de sedimentos, sendo a região com maiores valores de CP. EE mostra discordância negativa para essa área, isto é, os fatores de manejo são compatíveis com a capacidade de uso da terra, nesses locais, principalmente pelo acúmulo de material. O restante do terreno apresenta discordâncias positivas, em que a probabilidade de o processo erosivo ocorrer é maior, isto é, nas áreas com cultivo de cana-de-açúcar. 
(a)
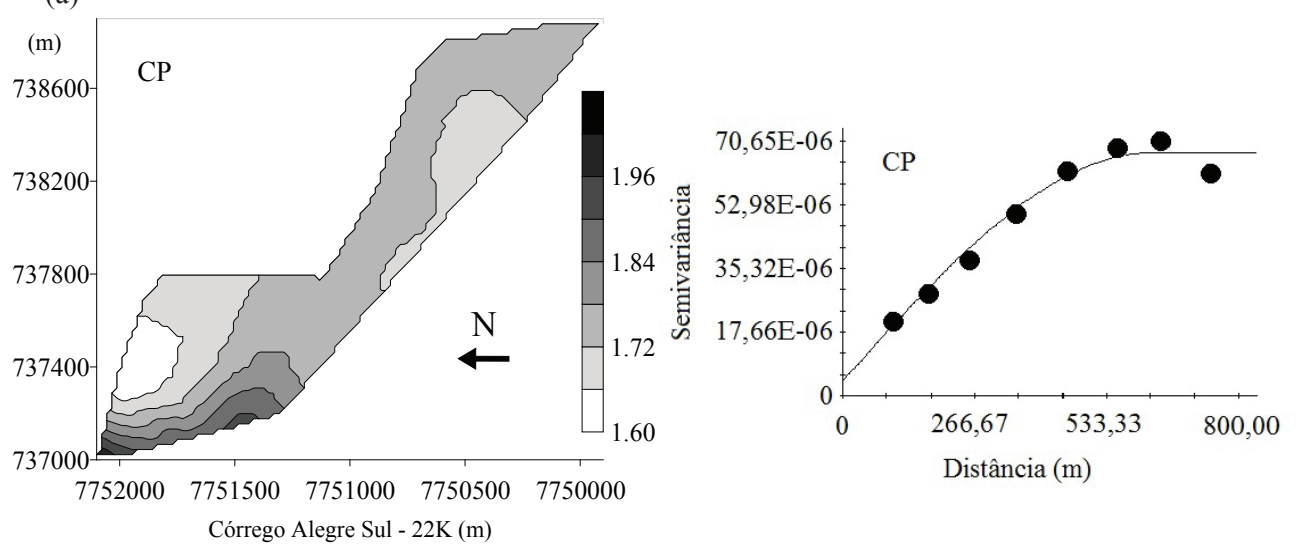

(b)
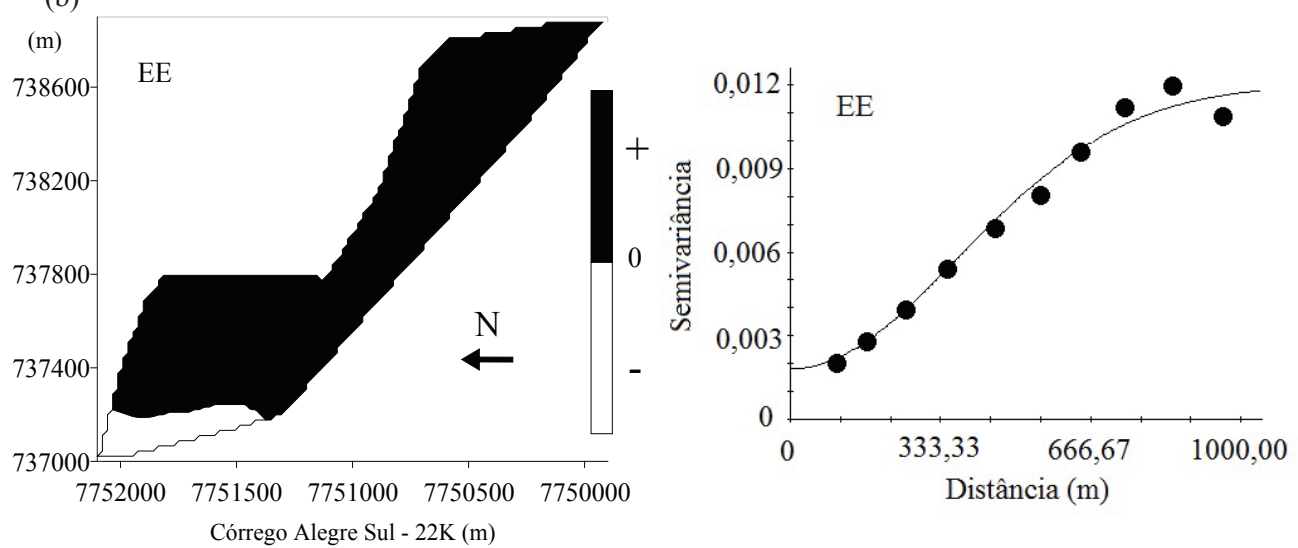

Figura 5. Mapas de isolinhas e semivariogramas: (a) fator antrópico (CP), adimensional; e (b) expectativa de erosão (EE), adimensional (Colômbia, SP, 2009).

Diversos trabalhos apontam a relação direta do relevo com as perdas de solo, principalmente em relação às pedoformas da paisagem (Barbieri et al. 2008, Campos et al. 2008, Leão et al. 2010, Santos et al. 2011). No entanto, quando as condições naturais são ideais, como relevo relativamente plano e solo estável, as perdas de solo são altamente influenciadas e condicionadas pelos fatores antrópicos.

Por meio das discordâncias obtidas, podem ser destacadas as maiores potencialidades dos processos erosivos na área, contidas em pontos específicos do relevo, como áreas convexas, mas mostrando uso e ocupação inadequados nas demais áreas, como o pH nas áreas de citrus, o que sugere a necessidade de zonas de manejo específico.

\section{CONCLUSÕES}

1. A análise espacial aponta zonas onde o processo erosivo tende a ser mais intenso, principalmente nas pedoformas mais convexas do terreno.
2. O fator antrópico e a expectativa de erosão sobressaíram-se em grande parte da área, mostrando uso e manejo inadequados.

3. As zonas de manejo específico indicaram a necessidade de adequação das práticas de cultivo associadas a cada cultura na área.

\section{REFERÊNCIAS}

ALLEONI, L. R. F.; MELO, V. de F. Química e mineralogia do solo. Viçosa, MG: Sociedade Brasileira de Ciência do Solo, 2009.

AMARO FILHO, J.; ASSIS JÚNIOR, R. N.; MOTA, J. C. A. Física do solo: conceitos e aplicações. Fortaleza: Imprensa Universitária, 2008.

AULER, P. A. M. et al. Calagem e desenvolvimento radicular, nutrição e produção de laranja 'Valência' sobre porta-enxertos e sistemas de preparo do solo. Pesquisa Agropecuária Brasileira, Brasília, DF, v. 46, n. 3, p. $254-$ 261, 2011. 
BARBIERI, D. M.; MARQUES JÚNIOR, J. M.; PEREIRA, G. T. Variabilidade espacial de atributos químicos de um Argissolo para aplicação de insumos à taxa variável em diferentes formas de relevo. Engenharia Agrícola, Jaboticabal, v. 28, n. 4, p. 645-653, 2008.

BARRETO, A. G. O. P.; BARROS, M. G. E.; SPAROVEK, G. Bibliometria, história e geografia da pesquisa brasileira em erosão acelerada do solo. Revista Brasileira de Ciência do Solo, Viçosa, v. 32, n. 6, p. 2443-2460, 2008.

BERTONI, J.; LOMBARDI NETO, F. Conservação do solo. 6. ed. São Paulo: Ícone, 2008.

BOUAZIZ, M.; LEIDIG, M.; GLOAGUEN, R. Optimal parameter selection for qualitative regional erosion risk monitoring: a remote sensing study of SE Ethiopia. Geoscience Frontiers, Beijing, v. 2, n. 2, p. 237-245, 2011.

BUENO, C. R. P.; STEIN, D. P. Potencial natural e antrópico de erosão na região de Brotas, Estado de São Paulo. Acta Scientiarum, Maringá, v. 26, n. 1, p. 1-5, 2004.

CAIONE, G.; FERNANDES, F. M.; LANGE, A. Efeito residual de fontes de fósforo nos atributos químicos do solo, nutrição e produtividade de biomassa da cana-deaçúcar. Revista Brasileira de Ciências Agrárias, Recife, v. 8, n. 2, p. 189-196, 2013.

CAMPOS, M. C. C. et al. Variação espacial de perda de solo por erosão em diferentes superfícies geomórficas. Ciência Rural, Santa Maria, v. 38, n. 9, p. 2485-2492, 2008.

CANTARELlA, H.; QUAGGIO, J. A.; RAIJJ, B. V. Determinação da matéria orgânica. In: RAIJ, B. V. et al. (Eds.). Análise química para avaliação da fertilidade de solos tropicais. Campinas: Instituto Agronômico, 2001. p. 173-180.

DALCHIAVON, F. C. et al. Variabilidade espacial de atributos da fertilidade de um Latossolo Vermelho distroférrico sob sistema plantio direto. Revista Ciência Agronômica, Fortaleza, v. 34, n. 3, p. 453-461, 2012.

DAY, P. R . Particle fractionation and particle-size analysis. In: BLACK, C. A. (Ed.). Methods of soil analysis: chemical and microbiological properties. Madison: American Society of Agronomy, 1965. p. 545-566.

DENARDIN, J. E. Erodibilidade do solo estimada por meio de parâmetros físicos e químicos. 1990. 114 f. Tese (Doutorado em Agronomia - Solos e Nutrição Plantas) - Escola Superior de Agricultura "Luiz de Queiroz”, Universidade de São Paulo, Piracicaba, 1990.

EMPRESA BRASILEIRA DE PESQUISA AGROPECUÁRIA (Embrapa). Centro Nacional de Pesquisa de Solos. Sistema brasileiro de classificação de solos. 2. ed. Rio de Janeiro: Embrapa Solos, 2006.
GAMMA DESIGN SOFTWARE (GDS). GS+: Geostatistics for environmental sciences. 7. ed. Plainwell: GDS, 2004.

GOLDEN SOFTWARE. Surfer for Windows: user guide. Golden: Golden Software, 1997.

INSTITUTO DE PESQUISAS TECNOLÓGICAS DO ESTADO DE SÃO PAULO (IPT). Mapa geológico do Estado de São Paulo. São Paulo: IPT, 1981.

LAGROTTI, C. A. A. Planejamento agroambiental do município de Santo Antônio do Jardim - SP: estudo de caso na microbacia hidrográfica do córrego do Jardim. 2000. 115 f. Tese (Doutorado em Engenharia Agrícola) - Faculdade de Engenharia Agrícola, Universidade de Campinas, Campinas, 2000.

LANDIM, P. M. B. Sobre geoestatística e mapas. Terra Didática, Campinas, v. 2, n. 1, p. 19-33, 2006.

LEÃO, M. G. A. et al. Variabilidade espacial da textura de um Latossolo sob cultivo de citrus. Ciência e Agrotecnologia, Lavras, v. 34, n. 1, p. 121-131, 2010.

MONTANARI, R. et al. Variabilidade espacial de atributos químicos em Latossolo e Argissolos. Ciência Rural, Santa Maria, v. 38, n. 5, p. 1266-1272, 2008.

MOREIRA, M. C. et al. Desenvolvimento e análise de uma rede neural artificial para estimativa da erosividade da chuva para o Estado de São Paulo. Revista Brasileira de Ciência do Solo, Viçosa, v. 30, n. 6, p. 1069-1072, 2006.

OLDEMAN, L. R.; HAKKELING, R. T. A.; SOMBROEK, W. G. World map of the status of human-induced soil degradation. 2. ed. Wageningen: ISRIC, 1991.

RAIJ, B. V. et al. Análise química para avaliação da fertilidade de solos tropicais. Campinas: Instituto Agronômico, 2001.

SANCHEZ, R. B. et al. Variabilidade espacial de atributos do solo e de fatores de erosão em diferentes pedoformas. Bragantia, Campinas, v. 68, n. 4, p. 1095-1103, 2009.

SANTOS, H. L. et al. Suscetibilidade magnética na identificação de compartimentos da paisagem em uma vertente. Revista Brasileira de Ciências Agrárias, Recife, v. 6, n. 4, p. 710-716, 2011.

SANTOS, R. D. dos et al. Manual de descrição e coleta de solo no campo. 5. ed. Viçosa, MG: Sociedade Brasileira de Ciência do Solo, 2005.

SILVA, J. V. da et al. Perdas de solo e água por erosão hídrica em floresta equiânea em um Latossolo VermelhoAmarelo. Revista Brasileira de Ciências Agrárias, Recife, v. 5, n. 4, p. 579-584, 2010.

VIEIRA, S. R. Geoestatística em estudos de variabilidade espacial do solo. In: NOVAIS, R. F.; ALVAREZ, V. H.; SCHAEFER, C. E. G. R. (Eds.). Tópicos em ciência do 
solo. Viçosa, MG: Sociedade Brasileira de Ciência do Solo, 2000. p. 1-54.

VIEIRA, S. R. et al. Variabilidade espacial de atributos físicos e químicos relacionados com o estado de agregação de dois Latossolos cultivados no sistema de semeadura direta. Bragantia, Campinas, v. 70, n. 1, p. 185-195, 2011.

WEILL, M. A.; SPAROVEK, G. Estudo da erosão na microbacia do Ceveiro (Piracicaba, SP): I - Estimativa das taxas de perda de solo e estudo de sensibilidade dos fatores do modelo EUPS. Revista Brasileira de Ciência do Solo, Viçosa, v. 32, n. 2, p. 801-814, 2008.

WISCHMEIER, W. H.; SMITH, D. D. Predicting rainfall erosion losses: a guide to conservation planning. Washington, DC: Department of Agriculture, 1978. (Agriculture handbook, 537). 